\title{
PTEROCACTUS (CACTACEAE), NUEVO REGISTRO PARA LA FLORA DE CHILE $^{1}$
}

\author{
PTEROCACTUS (CACTACEAE), NEW RECORD FOR THE CHILEAN FLORA ${ }^{l}$
}

\author{
Roberto Kiesling ${ }^{2}$
}

\begin{abstract}
RESUMEN
Se menciona el género Pterocactus (Cactaceae) por primera vez para la flora de Chile, representado por $P$. hickenii Britton \& Rose. Además, esta especie, que se conocía sólo del extremo SE de la Patagonia, con las nuevas colecciones amplía su área conocida a toda la meseta patagónica al S de la latitud 4330’ S en Argentina.

Palabras claves: Cactaceae, Pterocactus, flora de Chile, nuevo registro.
\end{abstract}

\section{INTRODUCCION}

Pterocactus (K. Schumann, Monatsschr. Kakteenk.7: 6. 1897) es un género de Cactáceas perteneciente a la subfamilia Opuntioideae, que comprende hasta el momento 9 especies (Kiesling 1982). Las mismas se distribuyen en Argentina en la provincia botánica Patagónica (Cabrera 1976), donde crecen 5 especies, como también en la provincia del Monte, donde crecen otras cuatro.

Pterocactus comprende plantas aclimatadas a las severas condiciones de su medio, con raíces tuberosas, muchas veces de gran desarrollo y tallos subterráneos, adaptados a terrenos arenosos, subcilíndricos, sin areolas desarrolladas, cuyo cre-

${ }^{1}$ Trabajo de campo realizado con subsidios de la Cactus and Succulent Society (USA) y de la Myndel Botanical Fundation.

${ }^{2}$ Instituto de Botánica Darwinion. CONICET. Miembro de la Carrera del Investigador Científico. Argentina.
ABSTRACT

The genus Pterocactus (Cactaceae) is recorded for first time for the flora of Chile, represented by P. hickenii Britton \& Rose. Previous to this finding, the distribution of this species had been known only from the SE of Patagonia. The new records extend its geographic range to all of the patagonic plateau south of latitude $43^{\circ} 30^{\prime} \mathrm{S}$ in Argentina.

Keywords: Cactaceae, Pterocactus, Chilean flora, New record.

cimiento se interrumpe al alcanzar la superficie; y tallos aéreos muchas veces decíduos, globosos o cilíndricos, pequeños, cuyas areolas producen espinas. Otra adaptación interesante es la expansión laminar en forma de ala que presenta el arilo -o envoltura funicular-, una estructura seca de consistencia corchosa de origen funicular, de diferente desarrollo según las especies, y que constituye el único caso conocido de adaptación a la dispersión anemófila en cactáceas.

Las colecciones de herbario de las diferentes especies de Pterocactus son relativamente pocas, -a pesar de ser relativamente frecuentes en la naturaleza, ya que por su tamaño y color, y por vivir muchas veces al abrigo de pastos o de arbustos, son poco notables.

A pesar de las grandes diferencias de criterio acerca de la amplitud de los géneros que existe en esta familia, Pterocactus ha sido respetado por todos los autores por sus caracteres morfológicos y fenológicos tan diferentes a todos los demás. 
Recientemente Wallace \& Dickie (2002) confirmaron con análisis de ADN la ausencia de afinidades moleculares con otros géneros. También un trabajo sobre anatomía de semillas de Opuntioideae (Stuppy 2002) confirma la falta de afinidad con otros géneros de la subfamilia.

En estos momentos se están llevando a cabo tres estudios complementarios sobre este género: 1) estudios comparativos usando regiones no codificadoras del ADN de los cloroplastos, por el Dr. J. Hugo Cota-Sánchez y Antoine Lalumiere en el Department of Biology de la Universidad de Saskatchewan, Canadá, de todas las especies de Pterocactus y de representantes de otros géneros de la subfamilia Opuntioideae; 2) de diversos aspectos de su anatomía, que lleva a cabo la Lic. Ana Faigón, en la Cátedra de Anatomía Vegetal de la Univ. de Buenos Aires bajo la dirección de la Dra. Beatriz Galati; y 3) una revisión de los caracteres morfológicos y fenológicos considerados propios del género y comparación de los mismos entre las diversas especies, por el autor de esta nota.

La bibliografía sobre este género es escasa, aunque existe una revisión taxonómica más o menos reciente (Kiesling 1982). También en Flora Patagónica (Kiesling 1988) se encuentran descriptas e ilustradas varias especies.

\section{RESULTADOS}

Recientemente, durante un viaje a la Patagonia dedicado básicamente al estudio de este género, se realizaron diversas observaciones. Entre ellas resulta interesante la gran ampliación del área de Pterocactus hickenii, previamente conocido desde Comodoro Rivadavia hasta casi el estrecho de Magallanes (ca. Lat. $45^{\circ} 50^{\prime}$ hasta $50^{\circ} \mathrm{S}$ ), pero siempre entre la costa y sólo 100-150 km hacia el interior del continente. De acuerdo con lo que conocemos ahora, se extiende hacia el oeste, por toda la meseta hasta el pie de la cordillera y también hacia el norte, donde pudimos encontrarlo hasta la provincia de Chubut en la latitud $44^{\circ} \mathrm{S}$. Además, al preparar esta nota se encontró que material citado erróneamente en Flora Patagónica (leg. Kiesling 7003) para Santa Cruz, corresponde en realidad a Chubut, con lo que el límite norte conocido para esta especie es aproximadamente $43^{\circ} 30^{\prime} \mathrm{S}$.

Por sugerencia de Omar Ferrari de La Plata,
Argentina, entusiasta aficionado al cultivo de cactus, pudo ubicar también a Pterocactus hickenii en la localidad argentina de Los Antiguos (Chubut) y en la localidad chilena contigua de Chile Chico. Por limitaciones de tiempo no fue posible una mayor exploración en territorio chileno, pero seguramente en suelo y vegetación similar debe encontrarse aún más al oeste, por lo menos en las cercanías del Lago General Carrera.

Pterocactus hickenii Britton \& Rose, The Cactaceae 1: 31, figs. 31 y 32. 1919. Iconografía: Kiesling 1988, fig. 187.

Raíces tuberosas, fusiformes u obcónicas, de ca. $10 \mathrm{~cm}$ long. y $2 \mathrm{~cm}$ diám. Artejos subterráneos generalmente $2-4$, arrosariados, con raíces adventicias. Artejos supraterráneos globosos a cilindroides cortos, de 2-3 (-5) cm long. y 2-3,5 $\mathrm{cm}$ diám., verde-amarillentos a castaños o morados. Espinas escasas y cortas (o incluso ausentes) en artejos jóvenes, en los adultos 10-15 por areola, aciculares, mayormente rectas, unas 4 principales \pm rígidas, erguidas, oscuras (negras o castañas), muchas veces con punta clara (castaño claro a amarillo) y unas 11 radiales menores, de $0,5 \mathrm{~cm}$, también oscuras con el extremo claro.

Flores ca. de $3 \mathrm{~cm}$ long. y diám., con las areolas del receptáculo espinosas, similares a las de los tallos; perianto color amarillo hasta castañorojizo e incluso rojo intenso. Estilo cilíndrico $2 \mathrm{~cm}$ long., estigma con ca. 5-6 lóbulos, rojo-violáceos. Semillas cubiertas por el arilo de $7 \mathrm{~mm}$ de diám. total ( $5 \mathrm{~mm}$ sin el ala), con el ala estrecha e incompleta.

\section{Material Selecto estudiado}

Chile, XI Región. Chile Chico, 7-XI-2001, R. Kiesling 9972, cum M. Donath (CONC, SI).

Argentina, Chubut, Dpto. Florentino Ameghino, 185 km N Comodoro, RK 9937 (SI).

Chubut, Dpto. Llanguineo, E de Tecka, R. Kiesling 7003 (SI).

Santa Cruz, Dpto. Corpen Aike, Puerto Santa Cruz, Dusen 5419 (SI).

Si bien el material encontrado en Chile Chico se encontraba en estado vegetativo, es perfectamente identificable. Vive en suelo completamente arenoso, con grandes espacios desnudos entre los arbustos y hierbas, formando médanos en la orilla norte del 
Pterocactus en Chile: KIESLING, R.

Lago General Carrera. La vegetación se caracteriza por la dominancia de Colliguaja integerrima, acompañada por Sisyrhinchium sp., Bromus sp. y Junellia sp. Se observaron varias colonias de esta especie de cactus, la cual no es rara en la localidad.

\section{BIBLIOGRAFIA}

Cabrera, A. L. 1976. Fitogeografía Argentina, Enciclopedia Argentina de Agricultura y
Jardinería, Fasc. 1. ACME. Buenos Aires.

Kiesling, R. 1982. The genus Pterocactus. The Cactus and Succulent Journal of Great Britain 44: 5156.

Kiesling, R. 1988. Cactaceae, en Maevia N. Correa (ed.) Flora Patagónica 5: 218-243.

STUPPY, W. 2002. Seeds characters and classification of the Opuntioideae. Succulent Plant Research 6: 25-58.

Wallace, R. S. \& S. Dickie. 2002. Systematic implications of cloroplast DNA sequence variation in the Opuntioideae. Succulent Plant Research 6: 9-24. 